\title{
Associations of TP53 mutations, codon 72 polymorphism and human papillomavirus in head and neck squamous cell carcinoma patients
}

\author{
QI SHI $^{*}$, KANG XIAO $^{1 *}$, WEI WEI ${ }^{2 *}$, BAO-YUN ZHANG ${ }^{1}, \mathrm{CAO} \mathrm{CHEN}^{1}, \mathrm{YIN} \mathrm{XU}^{1}$, LI-NA CHEN $^{1}$, \\ YUN-TAO SONG ${ }^{2}$, XIAO MA ${ }^{2}$, NAI-SONG ZHANG ${ }^{2}$ and XIAO-PING DONG ${ }^{1,3}$
}

${ }^{1}$ State Key Laboratory for Infectious Disease Prevention and Control, Collaborative Innovation Center of Infectious Disease,
National Institute for Viral Disease Control and Prevention, Chinese Center for Disease Control and Prevention,
Beijing 102206; ${ }^{2}$ Key laboratory of Carcinogenesis and Translational Research (Ministry of Education),
Department of Head and Neck Surgery, Peking University Cancer Hospital and Institute, Beijing 100142;
${ }^{3}$ Chinese Academy of Sciences Key Laboratory of Pathogenic Microbiology and Immunology,
Institute of Microbiology, Chinese Academy of Sciences, Beijing 100101, P.R. China

Received July 15, 2013; Accepted August 20, 2013

DOI: $10.3892 /$ or.2013.2750

\begin{abstract}
To investigate the possible associations between mutations in TP53 and phenotypes of single-nucleotide polymorphisms (SNPs) in codon 72 (SNP72) with the expression profiles of p53 and human papillomavirus (HPV) infection, 93 pathologically diagnosed head and neck squamous cell carcinomas (HNSCCs) were included for study. Using PCR and direct sequencing, 45 TP53 mutations in 35 cases (37.6\%) were confirmed out of the 93 HNSCCs. P53 immunohistochemistry (IHC) confirmed $34(36.6 \%)$ cases with positive staining, including 22 cases with strong and 12 with weak positivity. IARC database and software analysis showed similar results that most of the mutated p53 proteins lost their normal function. Further statistical analysis found a negative correlation between 553 IHC and HPV IHC in the tissues from the group of other HNSCCs (of various sites other than the larynx) but not in the tissues from the laryngeal carcinomas. Analyses of
\end{abstract}

Correspondence to: Professor Xiao-Ping Dong, Department of Prion Disease, National Institute for Viral Disease Control and Prevention, Chinese Center for Disease Control and Prevention, 155 Changbai Road, Beijing 100052, P.R. China

E-mail: dongxp238@sina.com

${ }^{*}$ Contributed equally

Abbreviations: HNSCC, head and neck squamous cell carcinoma; HPV, human papillomavirus; SNP, single-nucleotide polymorphism; SNP72, single-nucleotide polymorphisms in codon 72; IHC, immunohistochemistry; PCR, polymerase chain reaction; TA class, transcriptional activity class; LSH, loop-sheet-helix; LOF, loss of tumorsuppressor function; GOF, gain of oncogenic function

Key words: TP53 mutation, p53 protein, SNP72, head and neck squamous cell carcinoma, human papillomavirus
SNP72 showed that the patients with the Arg phenotype had a significantly older age at disease onset when compared to patients with the Pro phenotype, particularly in the group of other HNSCCs. In addition, all cases with strong staining for p53 in the laryngeal carcinoma group had the Pro phenotype and all tumors with poor pathological differentiation in the group of other HNSCCs had the Pro phenotype. These data indicate that the profiles of TP53 mutations, SNP72 polymorphism, p53 IHC and HPV E6 IHC are distinct between the groups of laryngeal carcinoma and other HNSCCs.

\section{Introduction}

Head and neck squamous cell carcinomas (HNSCCs) are a group of common malignant cancers and account for more than 550,000 cases annually worldwide, and involve the oral cavity, larynx, hypopharynx and oropharynx (1). Tobacco use and alcohol consumption are two well-established risk factors, while epidemiological evidence suggests that a subgroup of HNSCCs results from the infection of high-risk types of human papillomavirus (HPV), particularly HPV16 $(2,3)$.

One of the most frequent alteration in HNSCCs is perturbation of the p53 pathway which regulates the cell cycle to conserve genomic stability and prevent mutations (4). Most of the TP53 mutations occur in exon 5-8. Traditional risk factors such as tobacco use lead to abrogation of p53 by mutation. In contrast, HPV obviates the need for mutation by encoding the E6 oncoprotein, which promotes degradation of wild-type p53 in the presence of the E6-AP complex (5), causing perturbation of cell cycle regulation. It has been found that HNSCCs with HPV infection show a lower frequency of mutations in TP53 when compared to HNSCCs without HPV infection $(6,7)$. However, whether this phenomenon exists in Chinese patients is not definitive.

The TP53 gene has more than 200 single-nucleotide polymorphisms (SNPs), most of which have no biological effects. However, SNP of codon 72 (SNP72) within exon 4, which 
encodes either proline (Pro, by codon CCC) or arginine (Arg, by codon CGC), appears to be able to influence the function of p53. Compared to TP53 encoding proline, TP53 encoding arginine is more effective at inducing apoptosis and preventing cells from neoplastic development $(8,9)$. Although the association of the SNP72 with various types of cancers including lung and cervical cancer has been reported $(10,11)$, the effect of the polymorphisms on HNSCCs with HPV infection remains uncertain.

In the present study, we analyzed mutations of TP53, the phenotype of SNP72 and the expression profiles of p53 in 93 Chinese patients with HNSCCs. Collectively with the HPV infection status and pathological and clinical data as previously described (12), possible correlations among the mutations in TP53, the phenotype of SNP72, the expression profiles of p53, HPV infection, and the pathological and clinical features were comprehensively analyzed in the group of laryngeal carcinomas and other HNSCCs (from other sites).

\section{Materials and methods}

Patients and specimens. A total of 93 patients with malignant squamous tumors were enrolled in the present study. The specimens consisted of 64 laryngocarcinoma and 29 other HNSCCs (5 oropharyngeal, 15 hypopharynx and 9 lip carcinoma). Details of the cases are provided in Table I. The professions of the patients varied and included laborers, teachers, medical staff and clients. The permanent residences of the patients were widely distributed throughout China. All samples were surgically removed and were conventionally fixed in $10 \%$ formalin and paraffin-embedded. Pathological assays verified that all cancers were squamous cell cancers. The pathological and clinical grades were assessed by pathologists and surgeons at the Peking University Cancer Hospital and Institute, respectively.

DNA extraction. Total DNAs from the tumor tissues were extracted from the paraffin-embedded tissue blocks with a commercial genomic DNA extraction FFPE kit (Qiagen). Briefly, 4 to 5 formalin-fixed, paraffin-embedded (FFPE) sections $(10 \mu \mathrm{m})$ were soaked in xylene and vortexed vigorously for at least $1 \mathrm{~h}$. Then the pellet was acquired and purified in accordance with the kit protocol. The DNA extraction was evaluated by electrophoresis on $2 \%$ agarose gel. Quality of the extracted DNAs was assessed with a settled PCR protocol with a pair of $\beta$-actin-specific primers.

PCR protocol for SNP72 in exon 4 and exons 5-8 of P53. SNP72 in exon 4 and exons 5-8 of the TP53 gene was amplified using polymerase chain reaction (PCR) in a Bio-Rad S1000 Thermal Cycler. The primer sequences and amplicons are listed in Table II. The reaction mixtures consisted of a total of $50 \mu \mathrm{l}$ containing $1 \mu \mathrm{l}$ of gDNA, $20 \mathrm{pmol}$ of sense and antisense primers, $21 \mu 1 \mathrm{RNase}$-free water and $25 \mu 12 \mathrm{X}$ Taq MasterMix (CW0682; CWBIO, China). Touchdown method was adopted to increase the specificity of the PCR products. Details of the PCR condition were as follows: denaturing at $95^{\circ} \mathrm{C}$ for $30 \mathrm{sec}$, annealing at $65^{\circ} \mathrm{C}$ for $45 \mathrm{sec}$ with a decrease of $1^{\circ} \mathrm{C}$ every cycle in the first 10 cycles and $55^{\circ} \mathrm{C}$ for the other 35 cycles, and extension at $72^{\circ} \mathrm{C}$ for $45 \mathrm{sec}$. All PCR assays were carefully
Table I. Clinicopathological features and p53 status in the HNSCC patients.

\begin{tabular}{lrrr}
\hline $\begin{array}{l}\text { Patient } \\
\text { characteristics }\end{array}$ & $\mathrm{N}$ & $\begin{array}{c}\text { TP53 mutation } \\
\mathrm{n} / \mathrm{N}(\%)\end{array}$ & $\begin{array}{c}\mathrm{p} 53 \mathrm{IHC} \text { positive } \\
\mathrm{n} / \mathrm{N}(\%)\end{array}$ \\
\hline $\begin{array}{l}\text { All patients } \\
\text { Gender }\end{array}$ & 93 & $35 / 93(37.6)$ & $34 / 93(36.6)$ \\
$\quad$ Male & 84 & $33 / 84(39.3)$ & $32 / 84(38.1)$ \\
Female & 9 & $2 / 9(22.2)$ & $2 / 9(22.2)$ \\
Age (years) & & & \\
$<40$ & 5 & $2 / 5(40.0)$ & $3 / 5(60.0)$ \\
$40-65$ & 69 & $26 / 69(37.7)$ & $24 / 69(34.8)$ \\
$>65$ & 19 & $7 / 19(36.8)$ & $7 / 19(36.8)$
\end{tabular}

Anatomical

diagnosis

\begin{tabular}{lrrr} 
Larynx & 64 & $22 / 64(34.4)$ & \multicolumn{1}{c}{$20 / 64(31.3)$} \\
Other carcinomas & 29 & $13 / 29(44.8)$ & \multicolumn{1}{c}{$14 / 29(48.3)$} \\
Pathological grades & & & \\
1 (carcinoma in situ) & 2 & $1 / 2(50.0)$ & $0 / 2(0)$ \\
2 (poorly diff.) & 15 & $5 / 15(33.3)$ & $7 / 15(46.7)$ \\
3 (moderately diff.) & 50 & $19 / 50(38.0)$ & $19 / 50(38.0)$ \\
4 (highly diff.) & 26 & $9 / 26(34.6)$ & $8 / 26(30.8)$ \\
Clinical stage & & & \\
I & 28 & $12 / 28(42.9)$ & $13 / 28(46.4)$ \\
II & 35 & $15 / 35(42.9)$ & $9 / 35(25.7)$ \\
III & 25 & $7 / 25(28.0)$ & $11 / 25(44.0)$ \\
IV & 5 & $1 / 5(20.0)$ & $1 / 5(20.0)$
\end{tabular}

HNSCCs, head and neck squamous cell carcinomas; IHC, immunohistochemistry.

carried out in the PCR laboratory with 4 separated rooms to avoid DNA contamination.

Direct sequencing. The PCR products were analyzed on $2 \%$ agarose gel and recovered from the gel using the QIAquick Gel extraction kit (cat. no. 28706; Qiagen, Germany) according to the manufacturer's instructions. Direct sequencing was performed using the same PCR primers by the ABI PRISM ${ }^{\mathrm{TM}}$ 3730xl DNA analyzer.

Immunohistochemical (IHC) assay. Paraffin sections (5 $\mu \mathrm{m})$ were routinely deparaffinized in xylene for $5 \mathrm{~min}$ twice and gradually rehydrated. Sections were quenched for endogenous peroxidases in $3 \% \mathrm{H}_{2} \mathrm{O}_{2}$ in methanol for $15 \mathrm{~min}$, pretreated with enzyme digestion antigen retrieval for $1 \mathrm{~min}$. After blocking in $1 \%$ normal goat serum to avoid nonspecific binding, the sections were incubated overnight at $4^{\circ} \mathrm{C}$ with a 1:500-diluted $\mathrm{mAb}$ for $\mathrm{p} 53$ (Novus). The sections were then incubated for 60 min with 1:1,000-diluted HRP-conjugated goat antimouse secondary antibody (Vector Laboratories, USA), and visualized by incubation with 3,3-diaminobenzidine tetrahydrochloride (DAB). The slices were dehydrated and mounted in Permount. For the negative controls, the primary antibody 
Table II. Primer sequences and amplicons of SNP72 and exon 5-8 in the TP53 gene.

\begin{tabular}{|c|c|c|}
\hline & Primer pairs $\left(5^{\prime}-3^{\prime}\right)$ & $\begin{array}{l}\text { Amplicons } \\
\text { (bp) }\end{array}$ \\
\hline SNP72 & $\begin{array}{l}\text { F: TTGCCGTCCCAAGCAATGGATGA } \\
\text { R: TCTGGGAAGGGACAGAAGATGAC }\end{array}$ & 199 \\
\hline Exon 5 & $\begin{array}{l}\text { F: TGTTCACTTGTGCCCTGACT } \\
\text { R: CAGCCCTGTCGTCTCTCCAG }\end{array}$ & 268 \\
\hline Exon 6 & $\begin{array}{l}\text { F: GCCTCTGATTCCTCACTGAT } \\
\text { R: TTAACCCCTCCTCCCAGAGA }\end{array}$ & 181 \\
\hline Exon 7 & $\begin{array}{l}\text { F: CTTGCCACAGGTCTCCCCAA } \\
\text { R: AGGGGTCAGAGGCAAGCAGA }\end{array}$ & 237 \\
\hline Exon 8 & $\begin{array}{l}\text { F: TTCCTTACTGCCTCTTGCTT } \\
\text { R: AGGCATAACTGCACCCTTGG }\end{array}$ & 231 \\
\hline
\end{tabular}

SNP72, single-nucleotide polymorphisms in codon 72 . F, forward; R, reverse.

for p53 was replaced with mouse non-immuno IgG. Images were captured with a DP70 digital camera mounted on a BX5 microscope (Olympus Optical, Japan) (12). The slides were analyzed separately by 2 independent observers blinded to the clinical data. The immunoreactivity in the malignant cells in each section was graded according to the number of positively stained nuclei: $<1 \%$ as negative, $\geq 1$ and $\leq 10 \%$ as weakly positive, $>10 \%$ as strongly positive.

Prediction of p53 protein function for the different mutations in each Transcriptional activity (TA) class. Functional classification was based on the overall TA of 8 different promoters (WAF1, MDM2, BAX, H1433s, AIP1, GADD45, NOXA and P53R2) as measured by Kato et al (13). For each mutant, the median of the 8 promoter-specific activities was calculated, and missense mutations were classified as 'non-functional' (median $\leq 20$ ), 'partially functional' (median $>20$ and $\leq 75$ ), 'functional' (median $>75$ and $\leq 140$ ) and 'supertrans' (median $>140$ ).

Sorting intolerant from tolerant(SIFT) class. SIFT (14) predicts whether an amino acid substitution affects protein function based on sequence homology and the physical properties of amino acids. Briefly, SIFT searches for similar sequences to the query sequence, chooses closely related sequences that may share similar function to the query sequence, obtains the alignment of these chosen sequences, and calculates normalized probabilities for all possible substitutions from the alignment. Positions with normalized probabilities $<0.05$ are predicted to be deleterious; those $\geq 0.05$ are predicted to be tolerated.

Statistical analysis. Statistical analysis was performed using Chi-square and Fisher's exact tests for correlations between groups in regards to HPV infection, SNP72 phenotype, P53 mutations and IHC. Mann-Whitney U test was used for the relationship between SNP72 and age. Probability values of
$<0.05$ were considered to indicate statistically significant results. All statistical analyses were performed by SPSS 20 (IBM, US).

Statement of ethics. Written consent for further investigation and publication was obtained from the patients or the patients' relatives, respectively. Usage of the stored human samples in this study was approved by the Ethics Committees of Peking University Cancer Hospital and Institute and the National Institute for Viral Disease Prevention and Control, China CDC.

\section{Results}

Mutations in the TP53 gene in laryngeal carcinoma and other HNSCCs. Altogether, 45 mutations within the TP53 gene were found in the tissues of 35 cases (37.6\%) out of the 93 recruited patients by direct sequencing, including 30 mutations in $34.4 \%(22 / 64)$ of patients in the group of laryngeal carcinoma and 15 mutations in $44.8 \%(13 / 29)$ of patients in the group of other HNSCCs. The detailed information of the individual mutations is documented in Tables I and III. Most of the mutations $(93.3 \%, 42 / 45)$ were missense and only 3 were nonsense. Six mutations generated stop codons, 2 deletions and 1 insertion led to frameshift mutations. The mutations at codon 245 within exon 7 and codon 271 within exon 8 were most frequently observed; both were detected in 4 cases. A mutation at codon 266 was observed in 3 cases and mutations at codons 248, 267 and 298 were detected in 2 cases, respectively. Meanwhile, most of the patients $(28 / 35,80 \%)$ had only one mutation in the TP53 gene. Only one patient had 4 mutations, 1 case had 3 mutations and 5 cases had 2 mutations. Two cases contained 2 mutations in the same exon region. Additionally, the locations of the mutations were frequently distributed at the hypervariable region of TP53.

Based on the structure domains of $\mathrm{p} 53$ described in the IARC p53 database, $6.7 \%(3 / 45)$ of the mutations affected the LSH (loop-sheet-helix) motif (codons 119-135 and 272-287), 11.1\% (5/45) affected the L2 domain (between codons 164 and 194), which was needed for the correct folding and stabilization of the central part of the protein, and 20\% (9/45) affected the L3 domain (between codons 237 and 250), directly involved in the interaction between the protein and DNA.

With the help of the protocol described by Kato et al (13) and an online software, the possible influences of the identified TP53 mutations on p53 protein function were analyzed and are summarized in Table III. Notably, the two methodologies revealed similar results. Among the 36 point-mutations, 25 were non-functional mutations that will abolish the normal function of p53. Four point-mutations were neutral ones that will not affect the p53 function. Other 5 point-mutations were stop codon mutations, which were not available by the two methods. Only 2 point-mutations (at codons 47 and 207) showed different consequences on p53 function by the two techniques. Additionally, there were 3 different frameshift insertions whose effects on p53 function were also unable to be predicted by the two techniques.

The numbers of patients with mutations in the different exons of the TP53 gene varied largely. Two patients $(2 / 92$, $2.2 \%$ ) contained mutations in exon $4,10(10 / 85,11.8 \%)$ in 
Table III. Individual TP53 mutations and the predicted functional changes of p53 proteins.

\begin{tabular}{|c|c|c|c|c|c|c|c|c|c|}
\hline \multirow[b]{2}{*}{ Group } & \multirow{2}{*}{$\begin{array}{c}\text { Sample } \\
\text { no. }\end{array}$} & \multirow[b]{2}{*}{ Exon } & \multirow{2}{*}{$\begin{array}{l}\text { Mutated } \\
\text { codon }\end{array}$} & \multirow{2}{*}{$\begin{array}{l}\text { Mutation by } \\
\text { sequencing }\end{array}$} & \multirow{2}{*}{$\begin{array}{c}\text { Amino acid } \\
\text { change }\end{array}$} & \multirow{2}{*}{$\begin{array}{l}\text { Change in } \\
\text { properties }\end{array}$} & \multirow{2}{*}{$\begin{array}{c}\text { Motif } \\
\text { structure }\end{array}$} & \multicolumn{2}{|c|}{ Protein function } \\
\hline & & & & & & & & TA class & SIFT class \\
\hline \multirow[t]{30}{*}{ Larynx } & 20 & 8 & 281 & $\mathrm{GAC}>\mathrm{AAC}$ & Asp $>$ Asn & Acid $>$ polar & LSH & NF & $\mathrm{D}$ \\
\hline & 23 & 7 & 249 & $\mathrm{AGG}>\mathrm{ACG}$ & Arg $>$ Thr & Alkaline>polar & L3 & NF & $\mathrm{D}$ \\
\hline & 37 & 5 & 163 & TAC $>$ TGC & Tyr $>$ Cys & Aromatic $>$ sulfurated & $\mathrm{S} 4$ & NF & $\mathrm{D}$ \\
\hline & \multirow[t]{2}{*}{38} & 5 & 158 & $\mathrm{CGC}>\mathrm{GGC}$ & Arg $>$ Gly & Alkaline>hydrophobic & $\mathrm{S} 4$ & NF & $\mathrm{D}$ \\
\hline & & 7 & 248 & $\mathrm{CGG}>\mathrm{CAG}$ & $\operatorname{Arg}>\mathrm{Gln}$ & Alkaline>polar & L3 & NF & $\mathrm{D}$ \\
\hline & 41 & 5 & 145 & CTG $>$ ATG & Leu $>$ Met & Hydrophobic $>$ polar & $\mathrm{S} 3$ & $\mathrm{~F}$ & $\mathrm{~N}$ \\
\hline & 46 & 7 & 245 & GGC $>$ TGC & Gly $>$ Cys & Hydrophobic $>$ polar & L3 & NF & $\mathrm{D}$ \\
\hline & \multirow[t]{2}{*}{50} & 6 & 194 & CTT $>$ CAT & Leu $>$ His & Hydrophobic $>$ alkaline & $\mathrm{L} 2$ & NF & $\mathrm{D}$ \\
\hline & & 7 & 245 & GGC $>$ AGC & Gly $>$ Ser & Hydrophobic $>$ polar & L3 & NF & $\mathrm{D}$ \\
\hline & 63 & 5 & 151 & $\mathrm{CCC}>\mathrm{TCC}$ & Pro $>$ Ser & Hydrophobic $>$ polar & $\mathrm{L}$ & NF & $\mathrm{D}$ \\
\hline & 64 & 7 & 242 & $\mathrm{TGC}>\mathrm{TTC}$ & Cys $>$ Phe & Polar>hydrophobic & L3 & NF & $\mathrm{D}$ \\
\hline & 65 & 8 & 266 & $\mathrm{GGA}>\mathrm{GAA}$ & Gly $>$ Glu & Hydrophobic >acid & S10 & NF & $\mathrm{D}$ \\
\hline & 66 & 8 & 298 & $\mathrm{GAG}>\mathrm{TAG}$ & Glu>stop & NA & C-term & NF & $\mathrm{D}$ \\
\hline & 69 & 5 & 175 & $\mathrm{CGC}>\mathrm{CAC}$ & Arg $>$ His & No change & L2 & NF & $\mathrm{D}$ \\
\hline & \multirow[t]{2}{*}{70} & 5 & 179 & $\mathrm{CAT}>\mathrm{CGT}$ & His $>$ Arg & No change & L2 & NF & $\mathrm{D}$ \\
\hline & & 8 & 298 & $\mathrm{GAG}>\mathrm{GGG}$ & Glu>Gly & Acid>hydrophobic & C-term & $\mathrm{F}$ & $\mathrm{N}$ \\
\hline & 74 & 6 & 207 & GAT $>$ AAT & Asp $>$ Asn & Acid $>$ polar & S6 & $\mathrm{F}$ & $\mathrm{D}$ \\
\hline & 79 & 7 & 259 & $\mathrm{GAC}>\mathrm{AAC}$ & Asp $>$ Asn & Acid $>$ polar & $\mathrm{L}$ & $\mathrm{PF}$ & $\mathrm{N}$ \\
\hline & 81 & 7 & 245 & $\mathrm{GGC}>\mathrm{GAC}$ & Gly $>$ Asp & Hydrophobic $>$ acid & L3 & NF & $\mathrm{D}$ \\
\hline & \multirow[t]{3}{*}{83} & 7 & Intron & AGGTC $>$ AGATC & & NA & NA & NA & NA \\
\hline & & 8 & 266 & GGA $>$ TGA & Gly>stop & NA & S10 & ND & ND \\
\hline & & 8 & 267 & $\mathrm{CGG}>\mathrm{CGT}$ & Arg $>$ Arg & No change & S10 & NA & NA \\
\hline & 84 & 4 & 47 & $\mathrm{CCG}>\mathrm{TCG}$ & Pro $>$ Ser & Hydrophobic $>$ polar & $\mathrm{N}$-term & S & $\mathrm{N}$ \\
\hline & \multirow[t]{4}{*}{85} & 4 & 51 & GAA $>$ TAA & Glu>stop & NA & N-term & ND & ND \\
\hline & & 7 & Intron & ACCCT $>$ ACTCT & & NA & NA & NA & NA \\
\hline & & 8 & 266 & GGA $>$ TGA & Gly>stop & NA & S 10 & ND & ND \\
\hline & & 8 & 267 & $\mathrm{CGG}>\mathrm{CGT}$ & Arg $>$ Arg & No change & $\mathrm{S} 10$ & NA & NA \\
\hline & 86 & 5 & 166 & 7 base deletion & $\begin{array}{c}\text { Frameshift } \\
\text { mutation }\end{array}$ & NA & $\mathrm{L} 2$ & NA & NA \\
\hline & 88 & 7 & 251 & ATC $>$ ATT & Lle $>$ Lle & No change & S9 & NA & NA \\
\hline & 92 & 8 & 303 & $\mathrm{AGC}>\mathrm{AAC}$ & Ser $>$ Asn & No change & C-term & $\mathrm{F}$ & $\mathrm{N}$ \\
\hline Other & 1 & 8 & 271 & GAG $>$ TTG & Glu-Val & Acid>hydrophobic & $\mathrm{S} 10$ & NF & $\mathrm{D}$ \\
\hline \multirow[t]{11}{*}{ carcinomas } & 2 & 8 & 271 & GAG $>$ TTG & Glu-Val & Acid>hydrophobic & S10 & NF & $\mathrm{D}$ \\
\hline & 5 & 7 & 241 & 1 base insert & $\begin{array}{c}\text { Frameshift } \\
\text { mutation }\end{array}$ & I & L3 & NA & NA \\
\hline & 8 & 5 & 168 & $\mathrm{CAC}>\mathrm{CCC}$ & His $>$ Pro & Alkaline>hydrophobic & $\mathrm{L} 2$ & NF & $\mathrm{D}$ \\
\hline & 9 & 7 & 245 & $\mathrm{GGC}>\mathrm{GAC}$ & Gly $>$ Asp & Hydrophobic $>$ acid & L3 & NF & $\mathrm{D}$ \\
\hline & 11 & 8 & 274 & GTT $>$ TTT & Val>Phe & No change & LSH & NF & $\mathrm{D}$ \\
\hline & 14 & 6 & 219 & $\mathrm{CCC}>\mathrm{TCC}$ & Pro $>$ Ser & Hydrophobic $>$ polar & S7 & NF & $\mathrm{D}$ \\
\hline & \multirow[t]{2}{*}{15} & 5 & 157 & 10 base deletion & $\begin{array}{c}\text { Frameshift } \\
\text { mutation }\end{array}$ & NA & $\mathrm{S} 4$ & NA & NA \\
\hline & & 8 & 271 & $\mathrm{GAG}>\mathrm{TTG}$ & Glu-Val & Acid>hydrophobic & S10 & NF & $\mathrm{D}$ \\
\hline & 16 & 8 & 271 & GAG $>$ TTG & Glu-Val & Acid>hydrophobic & S10 & NF & $\mathrm{D}$ \\
\hline & 17 & 5 & 146 & TGG $>$ TGA & Trp-stop & NA & $\mathrm{S} 3$ & ND & ND \\
\hline & 22 & 7 & 248 & $\mathrm{CGG}>\mathrm{CAG}$ & $\operatorname{Arg}>$ Gln & Alkaline $>$ polar & L3 & NF & $\mathrm{D}$ \\
\hline
\end{tabular}


Table III. Continued.

\begin{tabular}{cccccccccc}
\hline Group & $\begin{array}{c}\text { Sample } \\
\text { no. }\end{array}$ & Exon & $\begin{array}{c}\text { Mutated } \\
\text { codon }\end{array}$ & $\begin{array}{c}\text { Mutation by } \\
\text { sequencing }\end{array}$ & $\begin{array}{c}\text { Amino acid } \\
\text { change }\end{array}$ & $\begin{array}{c}\text { Change in } \\
\text { properties }\end{array}$ & $\begin{array}{c}\text { Motif } \\
\text { structure }\end{array}$ & TA class & SIFT class \\
\hline \multirow{2}{*}{ Other } & 27 & 6 & 220 & TAT>TGT & Tyr>Cys & No change & S & NF & D \\
& 30 & 8 & 286 & GAA $>$ TAA & Glu>stop & NA & LSH & ND & NA \\
& & 7 & Intron & GGTCA $>$ GGCCA & NA & NA & NA & NA \\
\hline
\end{tabular}

TA class, transactivation class: NF, non-functional protein; F, functional protein; PF, partial functional protein; S, supertrans; ND, no data; NA, not available. Sorting intolerant from tolerant (SIFT) class: D, deleterious; N, neutral; ND, no data; NA, not available.

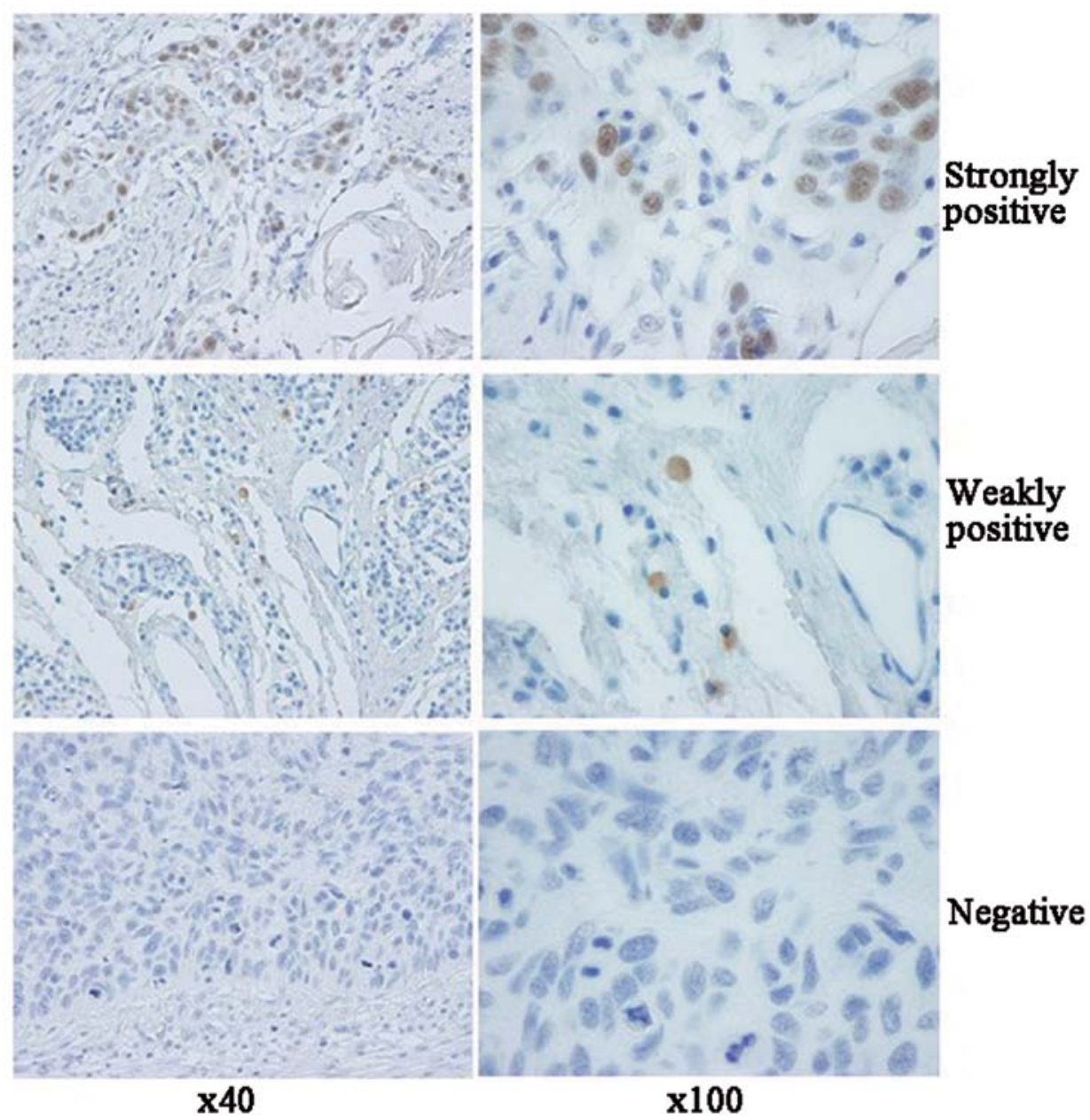

Figure 1. IHC assays of p53 in the tissues of HNSCCs with the anti-p53 monoclonal antibody. According to the percentage of positive nuclei in the cancer cells, the p53 expression profiles in IHC were classified into 3 groups: strongly positive $(>10 \%)$, weakly positive $(1-10 \%)$ and negative $(<1 \%)$, respectively, as shown from top to bottom. From left to right, images are viewed at a magnification of x40 and x100, respectively. IHC, immunohistochemistry; HNSCCs, head and neck squamous cell carcinomas.

exon 5, $4(4 / 92,4.3 \%)$ in exon $6,14(14 / 89,15.7 \%)$ in exon 7 and $13(13 / 92,14.1 \%)$ in exon 8 . Although various mutation rates were detected in exons, there was no significant difference in TP53 mutations between the laryngeal carcinoma group and the other HNSCC group.

Correlation of the TP53 mutation status with IHC for p53 protein. The expression profiles of $\mathrm{p} 53$ protein in sections of the tumor samples were analyzed by p53-specific IHC. Out of 93 tested primary HNSCCs, 34 showed positive staining for p53 protein. The brown color staining was distributed prominently in the malignant cells, and was localized in the cell nuclei (Fig. 1). Based on the semi-quantitative protocol for p53 immunostaining, the expression profiles of p53 were classified into strongly positive, weakly positive and negative. Twenty-two of the $34(64.7 \%, 22 / 34)$ p53-positive cases were characterized as strongly positive, while $12(35.3 \%, 12 / 34)$ were weakly positive. In the group of laryngeal carcinomas, 
Table IV. Relationship between mutations in TP53 exon 4-8 and p53 IHC.

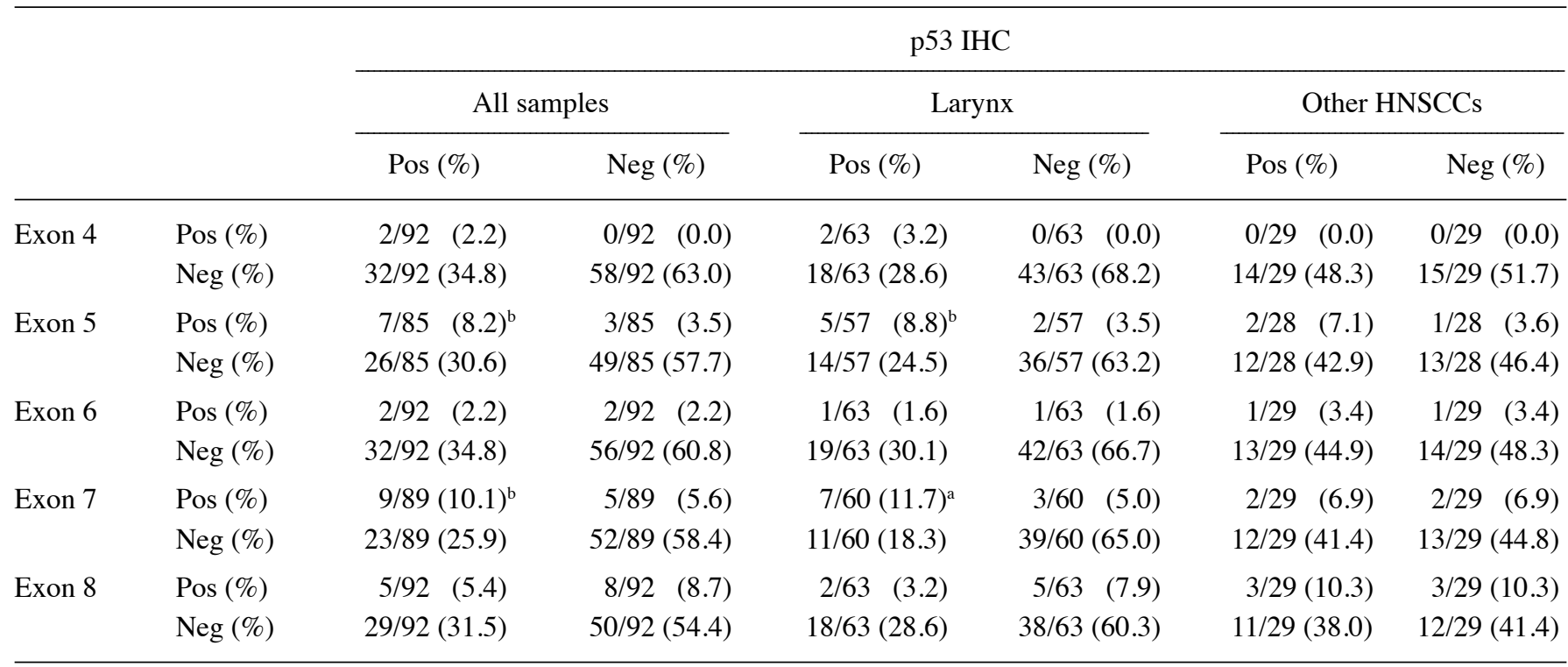

${ }^{\mathrm{a}} \mathrm{P}<0.01,{ }^{\mathrm{b}} \mathrm{P}<0.05$. IHC, immunohistochemistry; HNSCC, head and neck squamous cell carcinomas; Pos, positive; Neg, negative.

Table V. Relationship between HPV IHC and p53 IHC.

\begin{tabular}{|c|c|c|c|c|c|c|c|}
\hline & & \multicolumn{6}{|c|}{ p53 IHC } \\
\hline & & \multicolumn{2}{|c|}{ All samples } & \multicolumn{2}{|c|}{ Larynx $^{a}$} & \multicolumn{2}{|c|}{ Other HNSCCs ${ }^{\mathrm{b}}$} \\
\hline & & Pos (\%) & $\operatorname{Neg}(\%)$ & Pos (\%) & $\operatorname{Neg}(\%)$ & Pos (\%) & $\mathrm{Neg}(\%)$ \\
\hline \multirow[t]{2}{*}{ HPV IHC } & $\operatorname{Pos}(\%)$ & $12 / 93(12.9)$ & 17/93 (18.3) & 9/64 (14.1) & 9/64 (14.1) & $3 / 29(10.4)$ & $8 / 29(27.6)$ \\
\hline & $\operatorname{Neg}(\%)$ & $22 / 93(23.7)$ & $42 / 93(45.1)$ & $11 / 64(17.1)$ & $35 / 64(54.7)$ & $11 / 29(37.9)$ & $7 / 29(24.1)$ \\
\hline
\end{tabular}

${ }^{\mathrm{a}} \mathrm{P}<0.05,{ }^{\mathrm{b}} \mathrm{P}<0.1$. HPV, human papillomavirus; IHC, immunohistochemistry; Pos, positive; Neg, negative.

12 of $64(18.8 \%)$ cases were strongly positive for $\mathrm{p} 53,8$ cases were weakly positive $(12.5 \%)$ and 44 were negative (68.8\%). In the other HNSCC group, 10 of 29 (34.5\%) cases were strongly positive for p53, 4 cases were weakly positive $(13.8 \%)$ and 15 were negative $(51.7 \%)$. Despite a higher frequency of cases with strongly positivity for p53 in the other HNSCC group, no statistical difference in p53 expression profile was observed between the two groups.

In the cases with strong positivity for $\mathrm{p} 53,63.6 \%$ (14/22) of the cases contained mutation(s) in the TP53 gene, while 33.3\% $(4 / 12)$ of the cases with weak positivity for $\mathrm{p} 53$ presented with TP53 mutations. Further analyses revealed that mutations in exon $5(\mathrm{P}<0.05)$ and exon $7(\mathrm{P}<0.01)$ had a significant correlation with p53 positivity in the IHC assays in the laryngeal carcinoma group, as well as in the context of all tested patients $(\mathrm{P}<0.05)$, but not in that of the other HNSCC group (Table IV). No significant difference between the mutations in the other exons of TP53 and positivity for p53 in IHC was noted in all the tested groups (Table IV).

Correlation of p53 positivity and HPV E6 positivity in the IHC assays. Our previous study of the 93 patients with head and neck carcinomas demonstrated that 29 samples were HPV16/18 E6-positive in the IHC assays: $18(18 / 64,28.1 \%)$ in the laryngeal carcinoma group and $11(11 / 29,37.9 \%)$ in the other HNSCC group (12). Further analyses of the possible correlation between HPV E6 positivity and p53 positivity in the tumor tissues showed that in the laryngeal carcinoma group, an equal amount of HPV E6-positive cases were p53 positive, while a higher percentage of HPV E6-negative cases were p53 negative (Table V). In the group of other HNSCCs, markedly fewer numbers of patients with HPV E6 positivity were 553 positive, while a relatively higher percentage of HPV E6-negative cases were $\mathrm{p} 53$ positive (Table V). Moreover, the correlation between HPV DNA and p53 protein expression was analyzed, and no difference was found in the laryngeal carcinoma group, the other HNSCCs and all the patients tested.

Correlation of TP53 codon 72 polymorphism with HNSCCs. The codon 72 of the TP53 gene shows polymorphisms among human beings. Sequencing assays of the tumor samples of the 92 HNSCCs found that the numbers of Arg/Arg homozygotes, Pro/Pro homozygotes and Arg/Pro heterozygotes were 29/92 (31.5\%), 17/92 (18.5\%) and 46/92 (50.0\%), respectively. The 

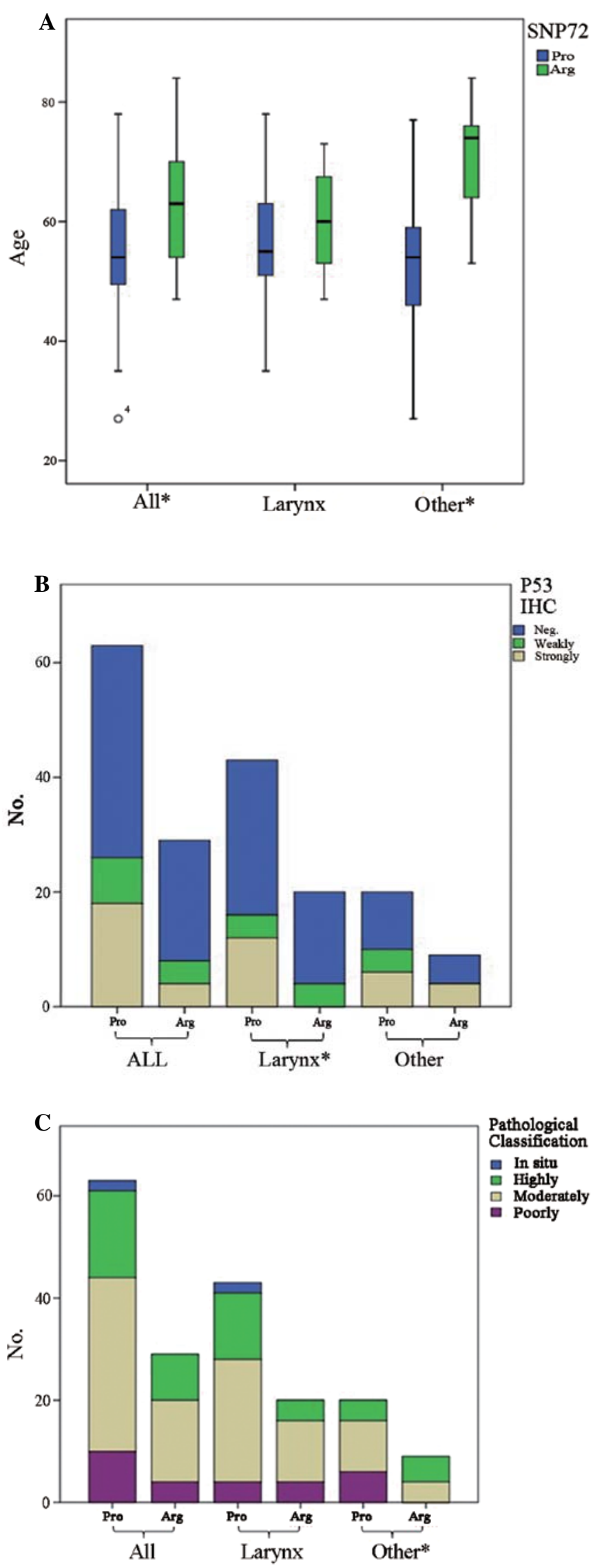

Figure 2. Association of SNP72 with the features of HNSCC patients. (A) Age of disease onset of the patients with Pro and Arg phenotypes. " $\mathrm{P}<0.05$. (B) $\mathrm{p} 53$ expression profiles in IHC with Pro and Arg phenotypes. ${ }^{*} \mathrm{P}<0.05$ (C) Pathological classifications of HNSCCs with Pro and Arg phenotypes. ${ }^{*} \mathrm{P}<0.05$. SNP72, single-nucleotide polymorphisms in codon 72; HNSCCs, head and neck squamous cell carcinomas; IHC, immunohistochemistry. potential correlations of the codon 72 polymorphism with a series of characteristics of HNSCCs were evaluated. It demonstrated that the average median age of disease onset (74 years) for patients with the Arg phenotype was significantly older than the age of disease onset (54 years) for the patient with the Pro phenotype in the group of other HNSCCs $(\mathrm{P}<0.05)$, whereas the age was slightly older but without statistical difference in the group of laryngeal carcinomas with the Arg phenotype (60 years) compared with patients with the Pro phenotype (55 years) (Fig. 2A). Assessment of the relationship with the pathological features of HNSCCs revealed that all poorly differentiated SCCs in the other HNSCC group had the Pro phenotype, while these phenotypes in poorly differentiated SCCs in the laryngeal carcinoma group were almost equal (Fig. 2B). Evaluation of the linkage of codon 72 polymorphism and the p53 expression profiles found that predominantly more HNSCC cases with the Pro phenotype had strong staining for p53 in the tumor tissues, particularly the laryngeal carcinomas in which all p53 strongly stained cases had the Pro phenotype (Fig. 2B). In contrast, the codon 72 polymorphism showed a weak correlation with the p53 expression profile in the other HNSCC group, as a similar frequency of cases with the Pro phenotype was observed in the cases with strong and weak positivity for $\mathrm{p} 53$. The pathological features of the carcinomas were classified into 4 degrees including in situ, highly differentiated, moderately differentiated and weakly differentiated cases. In the group of other HNSCCs, all the tumors with weak differentiation had the Pro phenotype, but there was no obvious difference in pathological classification in the laryngeal carcinoma group (Fig. 2C). Additionally, no significant association between SNP72 polymorphism and other factors, including HPV infection, clinical stage, tobacco use and alcohol consumption was found (data not shown).

\section{Discussion}

It has been established that TP53, a tumor-suppressor gene, plays a key role in organizing cellular responses to various types of stress, including DNA damage and oncogene activation followed by apoptosis, cell cycle arrest, senescence, DNA repair, cell metabolism or autophagy (15). Malfunction and mutations of p53 have been found in most types of human cancers, leading to deregulated p53 activity of proliferation and uncontrolled survival.

Most TP53 mutations in human cancers are missense mutations and focus on exon 5-8. In many cases, the mutations can either cause a loss of tumor-suppressor function (LOF) or, in some cases, a gain of oncogenic function (GOF) (16). A total of 45 mutations in 35 cases were detected in the patients recruited in our study. The relatively high frequency of point-mutations of p53 protein including codons 245, 248, 266, 267, 271 and 298 in the present study was similar with the commonly observed mutation regions of p53. All of these mutated codons were noted in the above 2 cases. For codon 245, all mutations, including Gly to Cys, Gly to Ser and Gly to Asp, led to a change from hydrophobic protein to a polar or acid one. At codon 271, 4 cases had the same mutation from Glu to Val, resulting in a change from acid protein to a hydrophobic one. Moreover, most of the mutations occurred in the L or S motif structure of p53. Compared with the muta- 
tion rates reported in other countries, the mutation rate in the present study $(35 / 93,37.6 \%)$ was slightly higher than the data in Indian $(17,18)$ HNSCC tissues which showed various TP53 mutations in $17-21 \%$ of patients, but was slightly lower than the TP53 mutations reported from USA, Europe and Japan ranging from 39 to $69 \%$ (19-21).

Based on the functional assays of a published protocol (13) and an online software, we forecasted that most of the identified point-mutations in TP53 (25/36) in this study p53 protein will result in changes of wild-type p53 to a non-functional form. A few point-mutations (4/36) are a neutral form that do not affect p53 function. Only the mutation at codon 47 in 1 case was predicted by one technique to be able to induce a change to the supertrans form that may result in stronger p53 activity. In addition, 5 stop codon point-mutations and 3 different frameshift insertions, which were not recognized with the above two methodologies, definitely interrupt the expression of normal p53 and eventually cause p53 dysfunction. Wide distributions in the non-functional p53-related point-mutations, as well as stop codon mutations and frameshift insertions in the TP53 gene in HNSCC cells emphasize again the essential role of p53 in carcinogenesis.

Normally, the half-life of wild-type p53 protein is short which makes it difficult to be detected by immunohistochemistry, whereas the mutated p53 protein is fairly stable which can easily be identified in tumor cells by immunohistochemistry (22). In agreement with previous data, we also determined that p53 overexpression is a frequently observed event in Chinese patients with HNSCCs (23) . However, we did not find any significant correlation between the p53 expression profiles in the tumor tissues and a series of parameters, including gender and age of the patients, various pathological classifications and clinical stage. Compared with previous studies that demonstrated that p53 overexpression is more prevalent in laryngeal tumors than in tumors in other anatomical sites (24), our data found a relatively lower positive rate of p53 in laryngeal tumors $(31.3 \%)$ than that in other HNSCCs (48.3\%), although no statistical difference was achieved.

HPV is another important etiologic factor, in addition to tobacco and alcohol for HNSCCs, particularly for oropharyngeal cancer (25). During the past few decades, HPV DNA has been detected in $25 \%$ of HNSCCs overall. More importantly, $45-100 \%$ of oral SCC cases are reported to be HPV-positive $(25,26)$. The data in our previous study also showed that HPV-positive rates had a significant association with the anatomic sites of tumors (12). In line with many published data, we also found that the p53-positive rate of patients with HPV16/18 E6 positivity was lower than that of the cases with HPV E6 negativity in the group of other HNSCCs. However, this phenomenon was not observable in the patients with laryngeal tumors, in which the p53-positive rates of the patients with HPV16/18 E6 positivity or negativity were comparable. These data highlight that the contrary correlation between HPV16/18 E6 positivity and p53 positivity was more likely detected in the SCCs that occurred in the oropharyngeal site. Further statistical analysis of the presence of p53 mutations and HPV infection or between HPV DNA and p53 protein expression failed to reveal any significant relationship in HNSCCs in our study. This possibly implies that either TP53 mutation or expression of high-risk HPV E6 may independently lead to p53 inactivation during the pathogenesis of HNSCCs.

The codon 72 polymorphism of p53 results in a substitution of Pro for Arg in the amino acid sequence and thus has an impact on the binding capacity and functional properties of p53 (27). Previous reports suggest that the p53 codon 72 polymorphism is associated with the susceptibility to several types of cancers and the survival of cancer patients $(28,29)$. In the present study, we found that the p53 Arg/Pro heterozygote was the major phenotype (49.5\%) among the cohort of 92 patients, while the homozygous phenotype Arg/Arg and Pro/Pro accounted for a lower percentage of 31.2 and $18.3 \%$, respectively. The SNP72 polymorphism has not been significantly linked with many factors, such as HPV infection, clinical stage, tobacco use and alcohol consumption. However, the cases having the Arg phenotype exhibited an obvious tendency to have an older age of disease onset and a higher degree of differentiation in pathology than the cases having Pro72. In addition, in the group of laryngeal carcinomas, all patients showing strongly positive p53 overexpression had the Pro phenotype. These results are in accordance with the conclusion that the wild-type Arg allele has a greater ability to localize to mitochondria, thereby inducing apoptosis to a greater exent than Pro72 $(30,31)$. It has been confirmed that Arg/Pro and Prp/Pro phenotypes of p53 codon 72 are significantly associated with an increased risk of secondary primary malignancy (SPM) in patients with HNSCCs (32). Whether such an association exists in our patient cohort deserves longterm follow-up.

\section{Acknowledgements}

This study was supported by the China Mega-Project for Infectious Disease (2011ZX10004-101, 2012ZX10004215), the Young Scholar Scientific Research Foundation of China CDC (2012A102) and the SKLID Development Grant (2012SKLID102 and 2011SKLID211).

\section{References}

1. Parkin DM, Bray F, Ferlay $\mathrm{J}$ and Pisani P: Global cancer statistics, 2002. CA Cancer J Clin 55: 74-108, 2005.

2. Gillison ML, Koch WM, Capone RB, et al: Evidence for a causal association between human papillomavirus and a subset of head and neck cancers. J Natl Cancer Inst 92: 709-720, 2000.

3. Sturgis EM and Cinciripini PM: Trends in head and neck cancer incidence in relation to smoking prevalence: an emerging epidemic of human papillomavirus-associated cancers? Cancer 110: 1429-1435, 2007.

4. Wang Z, Sturgis EM, Zhang Y, et al: Combined p53-related genetic variants together with HPV infection increase oral cancer risk. Int J Cancer 131: E251-E258, 2012.

5. Rautava $\mathbf{J}$ and Syrjänen S: Biology of human papillomavirus infections in head and neck carcinogenesis. Head Neck Pathol 6 (Suppl 1): S3-S15, 2012.

6. Braakhuis BJ, Snijders PJ, Keune WJ, et al: Genetic patterns in head and neck cancers that contain or lack transcriptionally active human papillomavirus. J Natl Cancer Inst 96: 998-1006, 2004.

7. Smeets SJ, Braakhuis BJ, Abbas S, et al: Genome-wide DNA copy number alterations in head and neck squamous cell carcinomas with or without oncogene-expressing human papillomavirus. Oncogene 25: 2558-2564, 2006.

8. Whibley C, Pharoah PD and Hollstein M: p53 polymorphisms: cancer implications. Nat Rev Cancer 9: 95-107, 2009. 
9. Dumont P, Leu JI, Della Pietra AC III, George DL and Murphy M The codon 72 polymorphic variants of p53 have markedly different apoptotic potential. Nat Genet 33: 357-365, 2003.

10. Buyru N, Altinisik J, Isin M and Dalay N: p53 codon 72 polymorphism and HPV status in lung cancer. Med Sci Monit 14 CR493-CR497, 2008

11. Storey A, Thomas M, Kalita A, et al: Role of a 533 polymorphism in the development of human papillomavirus-associated cancer. Nature 393: 229-234, 1998.

12. Wei W, Shi Q, Guo F, et al: The distribution of human papillomavirus in tissues from patients with head and neck squamous cell carcinoma. Oncol Rep 28: 1750-1756, 2012.

13. Kato S, Han SY, Liu W, et al: Understanding the function-structure and function-mutation relationships of p53 tumor suppressor protein by high-resolution missense mutation analysis. Proc Natl Acad Sci USA 100: 8424-8429, 2003.

14. SIFT Journal. http://sift.bii.a-star.edu.sg.

15. Tornesello ML, Buonaguro L and Buonaguro FM: Mutations of the TP53 gene in adenocarcinoma and squamous cell carcinoma of the cervix: a systematic review. Gynecol Oncol 128: 442-448, 2013.

16. Hollstein M, Moriya M, Grollman AP and Olivier M: Analysis of TP53 mutation spectra reveals the fingerprint of the potent environmental carcinogen, aristolochic acid. Mutat Res: Feb 17, 2013 (Epub ahead of print). doi: 10.1016/j.mrrev.2013.02.003.

17. Kannan K, Munirajan AK, Krishnamurthy J, et al: Low incidence of $p 53$ mutations in betel quid and tobacco chewing-associated oral squamous carcinoma from India. Int J Oncol 15: 1133-1136, 1999.

18. Heinzel PA, Balaram P and Bernard HU: Mutations and polymorphisms in the $p 53, p 21$ and p16 genes in oral carcinomas of Indian betel quid chewers. Int J Cancer 68: 420-423, 1996.

19. Saranath D, Tandle AT, Teni TR, et al: p53 inactivation in chewing tobacco-induced oral cancers and leukoplakias from India. Oral Oncol 35: 242-250, 1999.

20. Lukas J, Bohr VA and Halazonetis TD: Cellular responses to DNA damage: current state of the field and review of the 52nd Benzon Symposium. DNA Repair 5: 591-601, 2006.

21. Kilpivaara O and Aaltonen LA: Diagnostic cancer genome sequencing and the contribution of germline variants. Science 339: $1559-1562,2013$.
22. Bosch FX, Ritter D, Enders C, et al: Head and neck tumor sites differ in prevalence and spectrum of $p 53$ alterations but these have limited prognostic value. Int J Cancer 111: 530-538, 2004.

23. Zhou W, Ma Y, Yang H, Ding Y and Luo X: A label-free biosensor based on silver nanoparticles array for clinical detection of serum p53 in head and neck squamous cell carcinoma. Int J Nanomedicine 6: 381-386, 2011.

24. Peltonen JK, Helppi HM, Pääkkö P, Turpeenniemi-Hujanen T and Vähäkangas KH: p53 in head and neck cancer: functional consequences and environmental implications of TP53 mutations. Head Neck Oncol 2: 36, 2010.

25. Betiol J, Villa LL and Sichero L: Impact of HPV infection on the development of head and neck cancer. Braz J Med Biol Res 46: 217-226, 2013.

26. Tribius $S$ and Hoffmann M: Human papilloma virus infection in head and neck cancer. Dtsch Arztebl Int 110: 184-190, 2013.

27. Walter SD, Riddell CA, Rabachini T, Villa LL and Franco EL: Accuracy of p53 codon 72 polymorphism status determined by multiple laboratory methods: a latent class model analysis. PLoS One 8: e56430, 2013.

28. Chen SP, Hsu NY, Wu JY, et al: Association of p53 codon 72 genotypes and clinical outcome in human papillomavirus-infected lung cancer patients. Ann Thorac Surg 95: 1196-1203, 2013.

29. Zhou X, Gu Y and Zhang SL: Association between p53 codon 72 polymorphism and cervical cancer risk among Asians: a HuGE review and meta-analysis. Asian Pac J Cancer Prev 13: 4909-4914, 2012

30. Kaghad M, Bonnet H, Yang A, et al: Monoallelically expressed gene related to $\mathrm{p} 53$ at $1 \mathrm{p} 36$, a region frequently deleted in neuroblastoma and other human cancers. Cell 90: 809-819, 1997.

31. Thomas M, Kalita A, Labrecque S, Pim D, Banks L and Matlashewski G: Two polymorphic variants of wild-type p53 differ biochemically and biologically. Mol Cell Biol 19: 1092-1100, 1999

32. Li F, Sturgis EM, Chen X, Zafereo ME, Wei Q and Li G: Association of $p 53$ codon 72 polymorphism with risk of second primary malignancy in patients with squamous cell carcinoma of the head and neck. Cancer 116: 2350-2359, 2010. 